\title{
JOSÉ CORREA ORBEGOSO
}

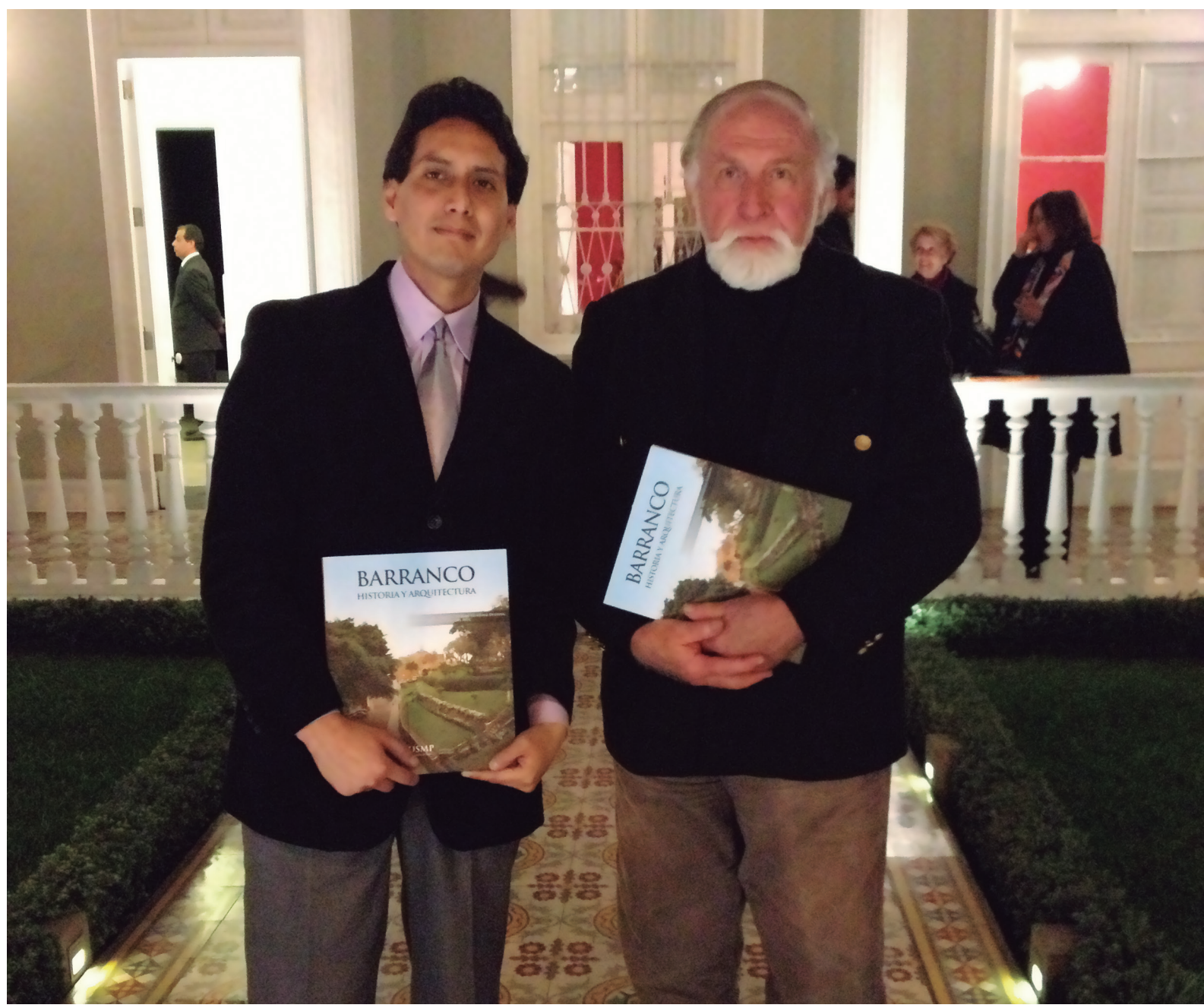

Figura 1. Arquitecto José Correa Orbegoso (a la derecha) en presentación del libro Barranco. Historia y Arquitectura, en el Museo Mario Testino (Barranco, Lima). Archivo fotográfico de José Hayakawa Casas, 2013.

A fines de octubre del año pasado dejó de existir el arquitecto José Correa Orbegoso, hecho que despertó enorme congoja entre quienes lo conocimos o compartimos su amistad. Su sensible fallecimiento nos trae a la memoria afectos y recuerdos de una existencia transcurrida con apasionamiento por la conservación del patrimonio cultural, y en especial la restauración de los monumentos históricos de nuestro país.

Fue un arquitecto con profunda vocación por su carrera profesional. En una entrevista que concedió en 2010, recordaba que su madre fue una de las primeras mujeres que estudió en la Escuela Nacional Superior Autónoma de Bellas Artes. Empleando su talento para las artes plásticas, ella le enseñó a dibujar desde pequeño, lo que despertó en él la inclinación por esas disciplinas. Cuando cursó sus estudios en la Facultad de Arquitectura, Urbanismo y Artes de la Universidad Nacional de Ingeniería (FAUA-UNI), entre 1961 y 1965, sus preferencias estuvieron orientadas hacia aquellos docentes que impartían asignaturas referidas a la Historia, la Estética y la conservación patrimonial. 
devenir Vol. 4, N8, JULIO - DICIEMBRE 2017, Pp. 5-7 - IN MEMORIAM I ISSN 2312-7562 | E-ISSN 2616-4949

UNIVERSIDAD NACIONAL DE INGENIERÍ, LIMA

Según su testimonio, tenía simpatía por las enseñanzas de Historia de la Arquitectura de José García Bryce, de Arte Universal de Carlos Rodríguez Saavedra, de Arqueología en el Perú de Frederic Engels y de Estética de Paul Linder. José recordaba de ese período de su formación inicial las lecciones del artista Juan Manuel Ugarte Eléspuru y el interés que despertó en su persona el curso de Restauración de Monumentos impartido por Víctor Pimentel, que había vuelto a la docencia después de capacitarse en Italia.

Rememoraba con mucha identificación a sus docentes integrantes de la Agrupación Espacio, Adolfo Córdova, Santiago Agurto y, en especial, Luis Miró Quesada. Más adelante, en la década del 70, cuando el arquitecto Correa desempeñaba la Dirección de Conservación del Patrimonio Cultural, tuvo la iniciativa de convocar a muchos de esos maestros a integrar las comisiones técnicas, y participar de los debates y los cursos de formación, para que aportasen sus experiencias y conocimientos.

Al año siguiente de concluir sus estudios en la Facultad de Arquitectura, José Correa obtuvo una beca y viajó por unos meses a Holanda, para seguir un curso de Renovación Urbana. En esa oportunidad constató que su verdadera aspiración era especializarse en Conservación y Restauración de Monumentos.

A raíz del sismo que afectó severamente los departamentos de Áncash y La Libertad en 1970, la Comisión de Reconstrucción de la zona afectada recibió asistencia técnica de la Organización de las Naciones Unidas para la Educación, la Ciencia y la Cultura (UNESCO) y designó como contraparte nacional al arquitecto Correa para elaborar proyectos encaminados al rescate de los monumentos de Trujillo de manera conjunta con el experto de UNESCO, el arquitecto boliviano José De Mesa. Al concluir esa misión, adelantándose en algunos meses al inicio de una beca de capacitación, viajó a España para pasar una temporada en Madrid y después se trasladó a Roma para capacitarse en el Centro Internacional de Estudios para la Conservación y Restauración de Bienes Culturales (ICCROM), creado por la UNESCO en esa ciudad. Simultáneamente fue admitido en el primer año de la Escuela de Perfeccionamiento para el Estudio y la Restauración de Monumentos de la Facultad de Arquitectura de la Universidad de Roma, La Sapienza.

Durante esa etapa de su formación especializada, se produjo la creación del Instituto Nacional de Cultura (INC) en el Perú, organismo público orientado a otorgar mayor importancia y protección al patrimonio cultural. Personas vinculadas a la cultura que habían contribuido a la gestación del Instituto, como el arquitecto Frederick Cooper y otros, consideraron que José Correa era la persona idónea para dirigir el área de conservación, por lo que le pidieron que regresara al país.

Para José no fue fácil truncar sus estudios en Roma, donde estaba instalado con su esposa e hijo. No obstante, la posibilidad de asumir un importante y honroso encargo constituyó un desafío que aceptó: retornó a su patria para asumir la Dirección Técnica de Conservación del Patrimonio Monumental del INC. Entre 1973 y 1978, su labor pública e institucional fue muy fructífera, no solamente por la moderna y eficiente organización que introdujo al área de conservación, sino porque puso todo su empeño para dar inicio un proyecto especial con la UNESCO, mediante el PER/71-539, que contó con cooperación técnica y asistencia económica del Programa de las Naciones Unidas para el Desarrollo (PNUD): un extenso y ambicioso programa de restauración de monumentos arqueológicos e históricos en función del turismo cultural en el eje Cusco-Puno (1973-1978). El referido proyecto internacional, enmarcado en el Plan Turístico y Cultural Perú-UNESCO (Plan COPESCO), continuó después de 1978 con un programa de ejecución de obras de restauración, sobre la base de los estudios y experiencias que se habían puesto en práctica desde 1973.

Además, José Correa fue el gestor e interlocutor para otro proyecto de patrimonio cultural andino llevado a cabo junto con el PNUD y la UNESCO, que permitió crear en Cusco cursos especializados de formación para arquitectos y técnicos restauradores de obras de arte entre 1975 y 1979. En ellos participaron becarios peruanos y de toda América Latina, y fueron impartidos por profesores de alto nivel, traídos por la UNESCO de diferentes confines del mundo. Para fortalecer este proyecto académico Correa tuvo que gestionar convenios y realizar continuos viajes por Europa y América del Sur, durante los cuales reveló su gran talento para las negociaciones con los organismos internacionales.

El proyecto que se llevó a cabo con la UNESCO en el Cusco tuvo un carácter multisectorial, y el arquitecto Correa fue nombrado miembro de la Comisión Especial del Plan COPESCO. Fue también miembro del Directorio de la Empresa Nacional de Turismo (1974-1978). En mérito a sus capacidades, la UNESCO contrató sus servicios 
como consultor en varias misiones internacionales, tales como: Ruta Maya (México y Guatemala, 1973), Turismo Cultural en Sucre y Potosí (Bolivia, 1978), y Conservación de Potosí (Bolivia, 1981).

Como suele ocurrir en el Perú, a fines de los años 70 algunos sectores y organismos públicos se politizaron al acercarse la transición del Gobierno Militar hacia la democracia. Entre ellos, el INC fue copado por militantes de un partido político. Esa situación hizo insostenible la permanencia de los cuadros técnicos especializados que se vieron obligados a dejar dicha institución, José Correa entre ellos. Entonces, por su jerarquía profesional, fue invitado a desempeñar el cargo de asesor de la Secretaría de Estado de Turismo (1979-1983).

Luego, Correa viró hacia el sector privado al fundar la empresa especializada Arquitectos, Restauradores e Ingenieros, Estudios y Servicios (Aries SRL), que estuvo activa entre 1983 y 2000. Allí tuvo como socio al arquitecto Ramiro Salas, con quien había trabajado en el INC en años anteriores. La empresa ejecutó importantes proyectos y obras, entre las más destacadas las que se realizaron por encargo de la compañía de minas Buenaventura, como las restauraciones de la Iglesia de Santo Domingo y la Iglesia de San Juan Bautista de Julcamarca, ambas en el departamento de Huancavelica. Asimismo, tuvieron gran trascendencia las obras de restauración que llevó a cabo en el Centro Histórico de Lima, como la Casa Jiménez, de la Compañía de Seguros Atlas (1984-1985); la Casa de La Riva, de la Asociación Entre Nous (1991); el Tribunal de la Inquisición, que se adaptó para alojar el Museo del Congreso (1997-1998); y el antiguo Tribunal Mayor de Cuentas, de la Casa de la Moneda (1998). Una obra significativa que le encargó el Ministerio de Relaciones Exteriores fue la restauración de la Casa de la Respuesta de Bolognesi, en Arica, Chile. El breve espacio de este obituario en homenaje al arquitecto Correa no permite mencionar otros destacados estudios y obras realizadas no solo en Lima, sino también en Trujillo, Cusco y otras ciudades del país.

Gracias a su amplia experiencia, fue un destacado profesor universitario, que enseñó en la maestría de Restauración de Monumentos y en la de Conservación del Patrimonio Edificado, así como en las asignaturas de Restauración de Monumentos de la FAUA-UNI. En la Facultad de Arquitectura y Urbanismo de la Universidad Ricardo Palma fue el profesor principal del Seminario de Centros Históricos y del curso de Restauración de Monumentos.

Durante más de una década ejerció la presidencia del Comité Nacional del Consejo Internacional de Monumentos y Sitios (ICOMOS-Perú), cargo que le permitió realizar intercambios de experiencias con otros profesionales y participar en reuniones internacionales. Sus pronunciamientos sobre los problemas que afectan al patrimonio cultural del país muchas veces fueron polémicos, pero siempre estuvieron orientados a la salvaguarda de los monumentos. En años posteriores a su gestión fue nombrado presidente honorario de dicha institución.

Como parte de su labor intelectual, siempre vinculada a la Historia y la conservación del patrimonio, publicó una serie de artículos en el diario La Gaceta de Trujillo. También se ocupó de La Muralla, la iglesia de la Compañía de Jesús, las casonas y otros monumentos de esa ciudad norteña en diversos diarios y revistas limeñas. Varios de sus artículos más recientes se publicaron en la revista de arquitectura Arkinka. Por esa existencia fructífera solo nos resta decirle non omnis moriar, porque sus afanes y desvelos serán siempre recordados.

Roberto Samanez Argumedo 